\title{
RASPI \\ SANG MAESTRO RONGGENG GUNUNG \\ RASPI MAESTRO OF RONGGENG GUNUNG
}

\author{
Euis Thresnawaty S. \\ Balai Pelestarian Nilai Budaya Jawa Barat \\ Jln. Cinambo 136 Ujungberung Bandung \\ e-mail: euisthresnawaty62@gmail.com
}

Naskah Direvisi:11 April 2016

Naskah Disetujui:4 Mei 2016

\begin{abstract}
Abstrak
Raspi adalah seorang maestro seni yang peduli pada lestarinya kesenian tradisional yang hampir punah, yaitu ronggeng gunung. Kesenian tradisional ini berasal dari Kabupaten Ciamis. Tarian ini muncul atas nama cinta dan dendam Dewi Siti Samboja, putri ke-38 Prabu Siliwangi karena suaminya Raden Anggalarang tewas di tangan bajak laut/bajo. Penelitian ini dilakukan untuk mengetahui siapakah Raspi, bagaimana kiprahnya sebagai ronggeng gunung, yang mampu bertahan sampai sekarang. Metode yang digunakan adalah metode sejarah yang meliputi heuristik, kritik, interpretasi, dan historiografi. Dari hasil penelitian yang dilakukan diperoleh informasi bahwa Raspi lahir di Dusun Karang Gowok, Kabupaten Ciamis tahun 1956. Sejak kecil ia hidup sendiri karena kedua orang tuanya telah bercerai. Usia 13 tahun, yaitu sekitar tahun 1970-an, Raspi lari dari rumahnya karena dipaksa kawin oleh orang tuanya. Saat pelarian itulah ia bertemu guru pertamanya sebagai penari ronggeng yaitu Embah Maja Kabun di Kampung Jubleg, Desa Panyutran, Kecamatan Padaherang, Kabupaten Ciamis.
\end{abstract}

Kata kunci: Raspi maestro, ronggeng gunung, kesenian tradisional.

\begin{abstract}
Raspi is a master of the art who concern about the preservation of nearly extinct traditional arts, namely Ronggeng Mountains. This traditional art is derived from Ciamis District. This dance appears in the name of love and revenge of Samboja Siti Dewi, daughter of the 38th Prabu Siliwangi Raden Anggalarang because her husband was killed by the pirates / bajo. This research is conducted to find out who is Raspi?, how his work as Ronggeng Mountain, is able to survive until now? The method used is the historical method which includes heuristics, criticism, interpretation, and historiography. The results are obtained that Raspi was born in Dusun Karang Kupa, Ciamis district in 1956. Since he was a kid, he lived alone because his parents had divorced. At age 13, which is about 1970, Raspi ran away because he was forced to marry by his parents. In his escape, he met his first teacher as a dancer Ronggeng, Embah Maja Kabun in Kampung Jubleg, Panyutran Village, District Padaherang, Ciamis District.
\end{abstract}

Keywords: Raspi maestro, ronggeng gunung, traditional arts.

\section{A. PENDAHULUAN}

Kabupaten Ciamis merupakan salah satu wilayah yang berada di Provinsi Jawa Barat. Memiliki jarak sekitar 13 kilometer arah tenggara dari ibu kota Provinsi Jawa Barat, yakni Bandung. Letak wilayahnya berada di antara $108^{\circ}$ sampai $108^{\circ} 43^{\circ}$ Bujur Timur dan $7^{\circ} 03 ` 39^{\prime \prime}$ 'sampai $7^{\circ} 39^{\prime} 36^{\prime \prime} \quad$ Lintang Selatan. Posisi Kabupaten Ciamis sangat strategis, berada di bagian timur wilayah Provinsi Jawa Barat yang berbatasan langsung dengan 
Provinsi Jawa Tengah, menjadi pintu gerbang di lintas jalur selatan yang menghubungkan Provinsi Jawa Barat dan Jawa Tengah. Daerah Ciamis menjadi daerah yang penting dalam arus perpindahan barang dan manusia di bagian selatan Pulau Jawa.

Ibu kota Kabupaten Ciamis adalah Ciamis Kota, yang berada di jalan jalur Bandung-Yogyakarta-Surabaya, juga dilintasi jalur kereta api lintas selatan, dengan stasiun terbesarnya Ciamis. Di bagian selatan kabupaten terdapat sebuah lapangan terbang perintis yang dinamai Nusawiru.

Pada tahun 2000 salah satu kecamatan di Kabupaten Ciamis, yaitu Kecamatan Banjar ditingkatkan statusnya menjadi kota administratif maka sejak tanggal 11 Desember 2002 ditetapkan menjadi kota otonom yang terpisah dari Ciamis. Saat itu jumlah kecamatan di Kabupaten Ciamis berkurang dari 40 kecamatan menjadi 36 kecamatan karena 4 kecamatan yang terdiri atas Kecamatan Banjar, Purwaharja, Pataruman, dan Langensari masuk ke dalam wilayah Kabupaten Banjar.

Pada tanggal 25 Oktober 2012 kembali terjadi pemekaran di wilayah Kabupaten Ciamis. Kecamatan Pangandaran ditingkatkan statusnya menjadi Kabupaten Pangandaran dengan pusat pemerintahan di Kecamatan Parigi. Akhirnya dari yang semula 36 kecamatan di Kabupaten Ciamis, setelah Pangandaran memisahkan diri menjadi 26 kecamatan karena 10 kecamatan yaitu: Kecamatan Cigugur, Cijulang, Cimerak, Kalipucang, Langkaplancar, Mangunjaya, Padaherang, Pangandaran, Parigi dan Sidamulih, menjadi bagian Kabupaten Pangandaran.

Saat ini Kabupaten Ciamis memiliki luas wilayah 143,387 ha dengan batasbatas wilayah sebagai berikut:

- Sebelah utara berbatasan dengan Kabupaten Majalengka dan Kuningan;

- Sebelah selatan berbatasan dengan Samudra Indonesia dan wilayah Kabupaten Ciamis;
- Sebelah barat berbatasan dengan Kabupaten Tasikmalaya dan Kota Tasikmalaya; dan

- Sebelah timur berbatasan dengan Kota Banjar dan Provinsi Jawa Tengah (BPS, 2016: 3).

Wilayah Kabupaten Ciamis secara administratif terbagi menjadi 26 kecamatan yang membawahi 258 desa dan 7 kelurahan, 2.904 Rukun Warga (RW) dan 9.142 Rukun Tetangga (RT). Kecamatan Banjarsari memiliki jumlah RT, dusun dan desa terbanyak, tetapi jumlah RW terbanyak ada di Kecamatan Rancah (BPS, 2016: 21). Kecamatan-kecamatan yang ada di wilayah Kabupaten Ciamis adalah: Lakbok, Banjarsari, Purwadadi, Pamarican, Cidolog, Cimaragas, Cijeunjing, Cisaga, Rancah, Tambaksari, Rajadesa, Sukadana, Ciamis, Baregbeg, Cikoneng, Sindangkasih, Cihaurbeuti, Sadanaya, Cipaku, Jatinagara, Panawangan, Kawali, Lumbung, Panjalu, Sukamantri, dan Panumbangan.

Jumlah penduduk yang tersebar di 26 kecamatan tadi pada akhir bulan Desember 2015 tercatat sebanyak 1.328.223 jiwa dengan tingkat kepadatan penduduk rata-rata $962 \mathrm{jiwa} / \mathrm{km}^{2}$. Dari segi penyebarannya $\quad 9,03 \%$ penduduk Kabupaten Ciamis bertempat tinggal di Kecamatan Banjarsari karena Kecamatan Banjarsari merupakan kecamatan terluas di Kabupaten Ciamis, sedangkan Kecamatan Ciamis 2,62\% sehingga menyebabkan kepadatan tertinggi yaitu 3.195 orang $/ \mathrm{km}^{2}$ (BPS, 2016: 43).

Adapun Kecamatan Banjarsari yang merupakan lokasi keberadaan Seni ronggeng gunung memiliki luas wilayah $162,62 \mathrm{~km}^{2}$ dengan jumlah penduduk Kecamatan Banjarsari pada 2015 berjumlah 125.950 jiwa, terdiri atas penduduk laki-laki sebanyak 63.606 jiwa dan jumlah penduduk perempuan sebanyak 62.344 jiwa. Jumlah penduduk tersebut apabila dilihat menurut kelompok umurnya maka yang paling banyak terdapat pada kelompok umur 10-14 tahun sebanyak 4.833 jiwa laki-laki dan 4.810 jiwa 
perempuan. Disusul oleh kelompok umur 05-09 tahun dengan jumlah 4.707 jiwa laki-laki dan 4.365 jiwa perempuan. Jumlah penduduk terbanyak ada di desa Cibadak yaitu sebanyak 7.422 jiwa, sedangkan kepadatan penduduk tertinggi ada di Desa Banjarsari sebanyak 774.5 jiwa $/ \mathrm{km}^{2}$. Jarak dari Kecamatan Banjarsari ke ibu kota Kabupaten Ciamis adalah sekitar $45 \mathrm{~km}$.

Secara geografis batas-batas wilayah yang mengelilingi Kecamatan Banjarsari adalah sebagai berikut:

- Sebelah utara berbatasan dengan

Kecamatan Purwadadi dan Kecamatan Mangunjaya;

- Sebelah selatan berbatasan dengan Kecamatan Langkaplancar dan

Kecamatan Parigi;

- Sebelah barat berbatasan dengan

Kecamatan Pamarican;

- Sebelah timur berbatasan dengan

Kecamatan Padaherang dan Kecamatan Sidamulih.

Secara administratif Kecamatan Banjarsari terdiri atas 22 desa, 78 dusun, 150 RW, 719 RT. Pembagian wilayah tersebut untuk mempermudah pembinaan penduduk yang tersebar di seluruh desa di wilayah Kecamatan Banjarsari. Di Kecamatan Banjarsari inilah, tepatnya di Dusun Cikukang RT 13/RW 03, Desa Ciulu tempat tinggal Raspi dan Sanggar Panggugah Rasa berada. Raspi sang ronggeng yang dengan gigihnya terus berupaya melestarikan kesenian tradisional ronggeng gunung.

Jenis kesenian ronggeng gunung hanya terdapat di daerah Kabupaten Ciamis dan berkembang di daerah pegunungan yang berfungsi sebagai ajang hiburan dan upacara adat. Kesenian ini tidak berbeda dengan ronggeng pada umumnya, yaitu kesenian tradisional yang menampilkan seorang penari atau lebih, yang diiringi lagu dari suara juru kawih atau sinden.

Akan tetapi khusus ronggeng gunung, ronggengnya hanya satu orang yang berperan sebagai penari sekaligus juru kawih, dan hanya diiringi tiga orang nayaga. Ronggeng gunung adalah wanita yang berperan sebagai penyanyi dan penari, yang ditunjang oleh aspek lain, yaitu penari laki-laki yang muncul dari penonton, yang dikenal dengan istilah pamogaran (Herdiani, 2003: 52).

Ronggeng gunung adalah tarian buhun yang penyajiannya sangat minimalis. Akan tetapi meskipun minimalis, ronggeng gunung memiliki kelebihan dari mayoritas tari Sunda. Apabila tari Sunda memberikan porsi sama antara gerakan tangan dan kaki, ronggeng gunung lebih menekankan pada gerakan kaki.

Dari sekian banyak keragaman bentuk dan jenis kesenian di Jawa Barat, ronggeng gunung merupakan salah satu seni pertunjukan yang cukup dikenal sehingga menjadi ciri khas dan identitas terutama untuk daerah Ciamis. Ronggeng gunung sampai sekarang masih mampu bertahan di tengah kesulitannya (Campaka, 2008: 3).

Seni ronggeng terbagi menjadi tiga jenis, berdasarkan asal penarinya: ronggeng gunung, penarinya berasal dari kawasan pengunungan. Ronggeng kaler penarinya berasal dari wilayah utara. Ronggeng kidul, penarinya berasal dari wilayah bagian selatan.

Dalam mengkaji permasalahan yang akan dibahas digunakan literatur terdahulu sebagai sumber rujukan dalam penelitian ini. Dari sejumlah sumber tertulis mengenai Raspi dan kesenian ronggeng gunung terdapat beberapa buku yang dapat djadikan sumber acuan yang saling melengkapi. Sumber pertama adalah "Lagu Kudup Turi dalam Kesenian Ronggeng Gunung di Ciamis Selatan" (2008), karya Gilang Campaka. Skripsi yang membahas tentang keberadaan ronggeng gunung dan kesulitan menjadi seorang ronggeng.

Sumber tertulis kedua adalah Skripsi yang berjudul "Perjalanan Ronggeng Gunung di Kabupaten Ciamis" (2009) karya Yayu Yuniawati. Skripsi ini 
membahas mengenai beberapa perubahan yang dialami kesenian ronggeng gunung sejak tahun 70-an hingga tahun 2009. Sumber ketiga adalah tulisan dari Angra Sutrisna tahun 2015 berjudul "Bi Raspi: Pelestarian Kesenian Ronggeng Gunung Ciamis" yang membahas tentang profil dan upaya Raspi melestarikan ronggeng gunung.

Permasalahan yang muncul dalam penelitian ini adalah: siapakah Raspi? Bagaimana kiprahnya sebagai penari ronggeng gunung yang mampu bertahan saat kondisi seperti sekarang? Adapun tujuan dari penelitian ini adalah mendeskripsikan secara singkat mengenai Raspi dan upayanya melestarikan kesenian tradisional ronggeng gunung, dengan harapan dapat memeroleh gambaran tentang kehidupan Raspi sebagai maestro ronggeng gunung.

\section{B. METODE PENELITIAN}

Penelitian ini menggunakan metode sejarah yang meliputi empat tahap: heuristik, kritik, interpretasi, dan historiografi. Heuristik yaitu tahap mencari dan menemukan sumber, baik sumber primer maupun sekunder. Untuk mendapatkan sumber tersebut peneliti langsung ke lapangan mendatangi instansi terkait yaitu Dinas Pendidikan dan Kebudayaan Kabupaten Ciamis. Perpustakaan Daerah Kabupaten Ciamis. Selain itu dilakukan wawancara dengan Bi Raspi dan putrinya yang bernama Nani Nurhayati. Langkah berikutnya adalah melakukan kritik sumber untuk mengetahui apakah sumbersumber tersebut valid dan dapat dipercaya. Sumber-sumber dikritik baik ekstern maupun intern. Selanjutnya adalah interpretasi, merupakan tahap menafsirkan fakta-fakta yang telah terkumpul dengan mengolah fakta yang telah dikritisi dengan merujuk beberapa referensi. Terakhir adalah historiografi yang bertujuan untuk merangkaikan fakta-fakta tersebut menjadi tulisan sejarah.

\section{HASIL DAN BAHASAN 1. Pengertian Ronggeng}

Pada masa sebelum perang, semua perempuan yang menyanyi atau menari di depan umum disebut ronggeng. Sekarang penyanyi dengan iringan gamelan kliningan atau wayang golek disebut sinden atau pesinden. Sebutan ronggeng hanya diberikan kepada perempuan yang bukan hanya menyanyi (kawih), tetapi juga melayani para penonton yang berminat untuk menari dengan imbalan uang (Rosidi et al., 2000: 551).

Ronggeng berasal dari kata renggana yang berarti perempuan pujaan dalam bahasa Sansekerta. Perempuan pujaan ini menari diiringi seperangkat alat musik tradisional. Tariannya berperan sebagai penghibur bagi tamu kerajaan. Diperkirakan ada sejak abad VII pada masa Kerajaan Galuh (Campaka, 2008: 4). Sementara kata gunung memiliki arti sebagai tempat yang permukaannya lebih tinggi dari dataran rendah (Kamus Besar Bahasa Indonesia, 2005: 376).

Pada masa penjajahan Belanda dan masa Thomas Stamford Raffles berkuasa, kesenian ronggeng telah populer. Menurut Raffles, ronggeng merupakan pertunjukan keliling yang dilakukan oleh perempuan berasal dari gunung. Mereka biasanya tampil di tempat-tempat pertunjukan resmi. Mereka tampil dalam pertunjukan keliling dan berpindah-pindah dari satu tempat ke tempat lainnya dalam ruang publik, acapkali juga mereka tampil di rumah dan halaman rumah para bangsawan juga penguasa Belanda (Holt, 2000: 39).

Ronggeng adalah perempuan yang memiliki banyak peran dalam kesenian ronggeng gunung. Dalam setiap pertunjukan kesenian tersebut, dia akan bertindak sebagai penari sekaligus sebagai penyanyi. Selain itu, dia juga akan berperan sebagai pemimpin dalam sejumlah ritual upacara yang melibatkan kesenian ronggeng gunung di dalamnya (Herawati, 2005: 12). Tidak dapat dipungkiri dan hampir dapat dipastikan, ronggeng merupakan pemain utama yang menjadi 
titik sentral dari alur pertunjukan ronggeng gunung. Kelangsungan pertunjukan tersebut juga sangat bergantung pada kehadiran ronggeng. Berjalan dan berhentinya pertunjukan dikendalikan oleh seorang ronggeng.

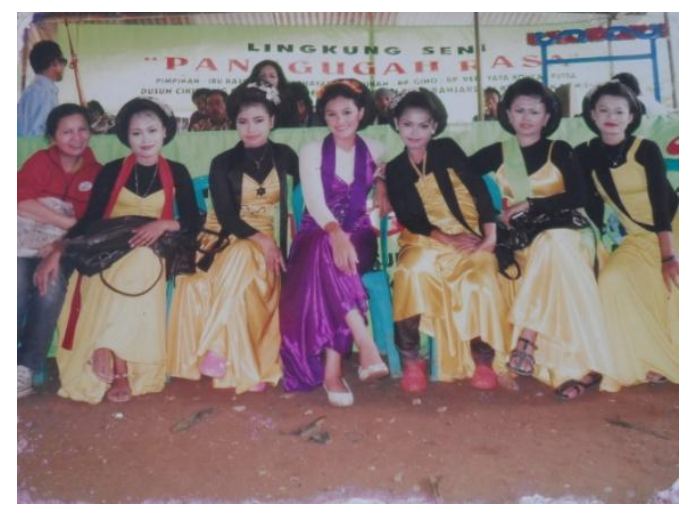

Gambar 1: Para penari Ronggeng Kaler Sumber: BPNB Bandung 2013.

Tidak ada batasan umur untuk menjadi seorang ronggeng. Seperti pengalaman ronggeng yang populer saat ini di Ciamis, Raspi mengaku menjadi ronggeng sejak usia 13 tahun. Meskipun demikian, tidak setiap perempuan bisa dengan mudah menjadi ronggeng. Ia harus melalui seleksi yang ketat dan betul-betul memiliki kemampuan menari, menyanyi, juga berparas jelita. Tidak heran, pada saat itu ronggeng termasuk orang terpandang dalam lingkungan dan keluarganya.

Sebagian besar persyaratan untuk menjadi ronggeng memang masih seperti itu, kecuali keharusan berparas cantik tidak terlalu penting lagi. Handal dalam kemampuan menari dan menyanyi merupakan tuntutan utama bagi seorang ronggeng. Dari dua keahlian itu, menyanyi merupakan yang paling penting. Dia harus mampu menyanyi dalam waktu yang lama, karena dia akan menyanyi sepanjang pertunjukan ronggeng gunung berlangsung. Selain itu, dia dituntut mahir melakukan olah vokal dengan tingkat kesulitan yang tinggi, seperti menyanyi dengan suara yang melengking tinggi, keras, dan meliuk-liuk. Tak heran, alunan suara ronggeng tetap akan terdengar, sekalipun tanpa bantuan pengeras suara (Adeng, 2013: 54).

Kesenian ronggeng gunung memang menyimpan kekuatan pada nyanyiannya yang lahir dari kekuatan dan karakter vokal seorang ronggeng. Nyanyian yang dilantunkan seorang ronggeng sesekali terdengar sendu, namun lebih banyak berupa suara lengkingan panjang yang menyayat-nyayat. Tinggi rendah nada muncul tak terduga dan hanya bisa dilakukan oleh mereka yang terlatih dalam olah suara dan nafas (Campaka, 2008: 4).

Durasi pementasan tarian yang disertai tembang biasanya memakan waktu cukup lama. Kalaupun bergabung dengan seni lain, ronggeng gunung ditempatkan di acara terakhir dan seringkali selesai menjelang subuh (Andayani, 2006: 26).

Ketika hendak tampil dalam suatu pertunjukan, sang ronggeng tentu saja harus merias diri dan mengenakan kostum panggung agar tampak istimewa dan memukau. Seorang ronggeng biasanya mengenakan busana dan tata rias yang khas namun tampak sederhana. Rambut disanggul secara tradisional, dengan ukuran sanggul yang cukup besar. Riasan wajah pun tidak terlalu mencolok, namun tetap menunjukkan penampilan yang berbeda dengan dandanan sehari-hari. Yang pasti aura kecantikan seorang ronggeng yang mempesona terpancar pada saat itu.

Telinga ronggeng dipasangi subang berukuran agak besar. Pada lehernya dikalungkan kalung panjang berwarna keemasan, serta sampur yang warnanya serasi dengan bajunya. Warna yang dipilih biasanya warna yang cukup menyala, seperti merah. Model busana yang dikenakan ronggeng berbentuk kebaya sederhana berlengan pendek atau panjang. Payet dan renda keemasan menghiasi bagian bawah kebaya dan belahan depan kebaya. Secara terpisah, pada bagian tengah kebaya dipasang apok, yakni hiasan dari kain yang melingkar di bagian pinggang ronggeng. Apok dihiasi payet dan renda keemasan pada bagian sisi- 
sisinya. Pasangan kebaya merah yang dikenakan oleh ronggeng adalah kain panjang. Pergelangan tangan sang ronggeng dihiasi gelang keemasan. Dengan dandanan seperti itu, seorang ronggeng sudah siap untuk tampil menghibur para pencinta kesenian ronggeng.

Hal-hal yang disyaratkan untuk menjadi seorang ronggeng bukan sesuatu yang mudah untuk dilakukan. Seperti telah disebutkan tadi bahwa kesulitan yang paling utama terletak pada kemampuan berolah vokal yang cukup unik. Perempuan muda di Ciulu misalnya, lebih memilih menjadi penyanyi dangdut atau penyanyi organ tunggal daripada menjadi ronggeng. Mereka tidak memiliki kesabaran yang lebih untuk mendapat kemampuan menyanyi seperti itu. Belajar menjadi ronggeng memang memerlukan waktu yang cukup panjang. Sementara itu, anak muda sekarang umumnya ingin belajar dengan cepat agar dapat segera menghasilkan uang.

Tak heran, perempuan yang berprofesi sebagai ronggeng terbilang langka sampai sekarang. Saat ini, hanya ada satu perempuan yang begitu serius menekuni dunia itu, yakni Raspi atau lebih dikenal dengan panggilan Bi Raspi. Dia pun sudah tidak muda lagi, karena telah berumur di atas 50 tahun. Dalam dirinya terbersit keinginan untuk mewariskan keahliannya menjadi ronggeng kepada generasi muda, namun dia kesulitan menemukan orang yang bersedia menghabiskan waktunya menjadi ronggeng.

Melihat kenyataan tersebut, bukan hanya Bi Raspi yang merasa sedih dan khawatir. Para pecinta kesenian ronggeng gunung dan berbagai pihak yang berhubungan dengan bidang kesenian pun merasakan hal yang sama. Ironis memang, eksistensi seni tradisi warisan leluhur yang kaya akan nilai-nilai kehidupan itu berada dalam kondisi kritis karena hambatan regenerasi. Jika Raspi meninggal, barangkali ronggeng gunung tinggal kenangan saja, karena generasi penerusnya belum muncul.

\section{Kisah Sejarah di Balik Kesenian Ronggeng Gunung}

Asal-usul kesenian ronggeng gunung, salah satunya merujuk pada cerita rakyat yang berhubungan dengan seseorang yang bernama Dewi Siti Samboja. Kisah selengkapnya dapat dilihat pada uraian berikut ini.

Pada zaman dahulu, di ujung Pananjung berdiri sebuah kerajaan yang dipimpin seorang raja bernama Raden Anggalarang. Istri sang raja bernama Dewi Siti Samboja, yang kelak akan disebut Dewi Rengganis. Raden Anggalarang mendirikan sebuah kerajaan di sana atas kehendak sendiri. Dia sengaja meminta kepada ayahnya, yaitu Prabu Haur Kuning, yang sedang memimpin kerajaan di daerah Galuh.

Sejak awal, Prabu Haur Kuning sudah memiliki firasat yang kurang baik terhadap niat anaknya, yang ingin membangun sebuah kerajaan. Firasat itu muncul karena dia mengetahui situasi dan kondisi tempat tersebut. Lokasi untuk kerajaan anaknya berada tidak jauh dari pinggir pantai. Wilayah tersebut, apalagi di ujung Pananjung, merupakan tempat persinggahan andar-andar atau bajo. Oleh karena itu, wilayah tersebut kemudian disebut Pangandaran. Mereka dikenal sebagai orang-orang jahat. Sekalipun kerajaan yang dikehendaki anaknya berdiri, diperkirakan keberadaan kerajaan tersebut tidak akan berumur lama oleh ayahnya (Depdikbud Ciamis, 1998: 4).

Raden Anggalarang tidak mengindahkan kekhawatiran ayahnya. Dia tetap bersikeras untuk mendirikan kerajaan sampai selesai. Dalam menyelesaikan pekerjaan besar tersebut, dia dibantu para pengikutnya, juga didampingi oleh Patih Kidang Pananjung dan Mama Lengser.

Apa yang dikhawatirkan Prabu Haur Kuning memang menjadi kenyataan. Tidak berapa lama setelah kerajaan itu berdiri, terjadi peperangan antara pasukan dari 
kerajaan pimpinan Kipatih Kidang Pananjung dengan para bajo (orang jahat) yang singgah di perairan tersebut. Tampaknya pimpinan bajo begitu bersemangat dalam peperangan itu, karena mengetahui istri pimpinan musuhnya sangat cantik. Sang permaisuri raja itu bernama Dewi Siti Samboja. Dalam peperangan tersebut, para bajo berhasil melumpuhkan Kipatih Kidang Pananjung sampai mati.

Kekalahan itu memaksa Raden Anggalarang untuk pergi dari tempat tersebut. Dia pun berembug dengan Mama Lengser untuk menentukan arah yang akan dituju. Mereka memutuskan untuk pergi ke tempat yang diperkirakan agak aman, yakni ke sebelah timur. Tibalah mereka di suatu tempat yang kemudian disebut Babakan, karena digunakan Raden Anggalarang untuk beristrirahat (mabakmabak).

Beberapa hari kemudian, para bajo mencium keberadaan rombongan Raden Anggalarang di tempat yang baru disinggahi. Selanjutnya, mereka langsung menyusun kekuatan untuk menyerang rombongan Raden Anggalarang, termasuk di dalamnya adalah rencana untuk memboyong sang permaisuri. Pimpinan para bajo memang sangat terpesona dan tergila-gila dengan kecantikan sang permaisuri.

Sementara para bajo sedang menyusun kekuatan, secara diam-diam Raden Anggalarang dan Mama Lengser memutuskan untuk pergi dan menghilangkan jejak. Mereka pergi ke barat dan menuju suatu tempat yang sekarang disebut Cikembulan. Nama Cikembulan diambil dari kata timbul, karena rombongan Raden Anggalarang menimbulkan diri atau muncul di tempat itu. Tak lama mereka tinggal di tempat tersebut, karena diperkirakan musuhnya juga sudah mengetahui posisi mereka. Kemudian, mereka berangkat lagi menuju barat dan sampai di pinggir laut yang kemudian dinamakan Batuhiu.
Setibanya di tempat itu, para pengikut Raden Anggalarang diperintahkan untuk menangkap ikan, karena dia akan beristirahat dan makan-makan dulu di sana. Diceritakan dia makan daging ikan sedikit saja, karena rasanya kurang enak. Kemudian dia membuang sisanya ke laut sambil berkata," jung siah hirup deui" atau "hiduplah kembali". Ternyata ikan itu tidak hidup lagi melainkan berubah menjadi gumpalan batu yang menyerupai ikan hiu (Sunda). Oleh karena itu, tempat tersebut kemudian diberi nama Batuhiu.

Setelah cukup lama beristirahat di sana, mereka kembali melanjutkan perjalanannya. Rombongan Raden Anggalarang pergi lagi menuju utara. Ketika matahari hampir terbenam, mereka sampai di suatu tempat yang sekarang namanya Serang. Dari tempat itu, Raden Anggalarang melihat ke timur, tampak jelas sekali kerajaannya. Dalam bahasa Sunda, dapat melihat dengan jelas dari jauh itu disebut nyerangkeun, yang asal katanya adalah serang. Oleh karena itu, tempat tersebut kemudian disebut Serang (Depdikbud Ciamis, 1998: 5).

Mereka melanjutkan perjalanan menuju utara, dan tiba di satu daerah yang kemudian dinamakan Padon Telu. Disebut demikian karena merupakan perbatasan dari tiga kecamatan, yaitu Kecamatan Parigi, Kecamatan Padaherang, dan Kecamatan Kalipucang. Di sana mereka mendapat informasi, bahwa musuhnya terus mengikuti kemana pun mereka pergi. Raden Anggalarang dan Mama Lengser berembug untuk mencari cara menyelamatkan sang permaisuri. Mereka sepakat, Dewi Siti Samboja besama Mama Lengser pergi ke utara, sedangkan Raden Anggalarang menuju selatan.

Sebelum melanjutkan perjalanan, Dewi Siti Samboja naik dulu ke sebuah gunung yang diperkirakan dapat melihat perjalanan sang suami, yakni Raden Anggalarang. Ketika dia melihat ke selatan, tampak suaminya sedang bertempur dengan para bajo yang sengaja terus mengejarnya. Tempat peperangan itu 
kemudian disebut Pasir Eurih. Ternyata suaminya mengalami kekalahan dalam pertempuran itu kemudian dibunuh, dan mayatnya diarak oleh para bajo. Oleh karena itu, tempat mengarak mayat tadi disebut Parakan. Sementara itu, tempat Dewi Siti Samboja melihat keadaan (nyawang dalam bahasa Sunda, yang kata asalnya adalah sawang) sang suami berperang disebut Sawangan (Depdikbud Ciamis, 1998: 6).

Dewi Siti Samboja bersama Mama Lengser segera berangkat ke utara hingga sampai di pinggir sungai yang kemudian disebut Citanduy. Di situ Dewi Siti Samboja bertemu dengan tukang rakit yang dapat menyeberangkan dirinya dan Mama Lengser. Begitu sampai di seberang, mereka berpesan agar tukang rakit tidak memberi tahu keberadaan mereka kepada orang lain. Tukang rakit pun tidak keberatan dengan permintaan itu.

Keesokan harinya, Dewi Siti Samboja sampai di sebuah anak Sungai Citanduy. Dia menemukan mayat seorang laki-laki muda, dan ternyata mayat itu adalah tukang rakit yang menyeberangkan mereka. Oleh karena itu, tempat menemukan mayat tersebut dinamakan Patimuan. Konon, dia tewas karena berkelahi dengan para bajo yang juga minta diseberangkan. Dia tidak meluluskan permintaan para bajo karena memenuhi keinginan Dewi Siti Samboja. Akibatnya, dia dibunuh para bajo dan mayatnya terbawa arus Sungai Citanduy.

Dari tempat tesebut, Dewi Siti Samboja dan Mama Lengser berangkat lagi menuju selatan dan sampai di daerah pegunungan yang kemudian disebut Tunggilis. Karena merasa lelah dengan kesengsaraannya, Dewi Siti Samboja menangis tak henti-hentinya di sana. Oleh karena itu, tempat tersebut dinamakan Tunggilis, dari kata tangis nu geulis atau tangisan si cantik jelita.

Di daerah pegunungan itu, Dewi Siti Samboja menyepi dan bertapa. Dalam keheningan, dia mendengar suara tanpa wujud. Intinya merupakan perintah agar rombongan Dewi Siti Samboja menyamar menjadi rombongan seni doger (ketuk tilu) bersama-sama dengan para pemuda setempat. Dewi Siti Samboja sendiri menjadi waranggana atau ronggengnya. Tujuan penyamaran itu tentu saja untuk menyelamatkan Dewi Siti Samboja beserta rombongannya dari kejaran para bajo. Berbulan-bulan Dewi Siti Samboja menyamar sebagai ronggeng bersama para pemuda yang ada di daerah pegunungan Kendeng. Dewi Siti Samboja pun mengganti namanya menjadi Dewi Rengganis.

Dikisahkan Prabu Haur Kuning mengutus salah seorang patihnya, yaitu Sawung Galing agar menelusuri keadaan anaknya yang mendirikan kerajaan di daerah pantai. Hal itu dilakukan karena dia mengetahui keadaan anaknya yang sedang mengalami kesulitan. Sampailah sang patih di daerah Pegunungan Kendeng. Di sana dia mendengar ada pergelaran kesenian yang dipimpin oleh Mama Lengser setiap malam. Pada suatu malam, Patih Sawung Galing mencoba menemui Mama Lengser. Ternyata Mama Lengser mengetahui patih itu adalah utusan dari Prabu Haur Kuning. Kedatangan sang patih untuk menemui keadaan anak dan menantunya.

Dewi Rengganis belum percaya kepada Sawung Galing sebagai utusan dari ayah (mertuanya). Dia meminta Sawung Galing agar bertanding dulu dengan para pemuda yang dipimpinnya. Ternyata, tak satu pun pemuda yang dapat menandinginya. Meskipun begitu, dia masih belum merasa yakin dengan kenyataan tersebut. Akhirnya, dia meminta patih untuk menunjukkan kekuatan lainnya sesuai dengan kapasitasnya sebagai seorang patih kerajaan.

Pada keesokan harinya, Patih Sawung Galing memperlihatkan ilmu kekuatannya. Dia mengambil sebuah lidi enau (Sunda: kawung) kemudian menancapkannya pada tebing batu yang ada di daerah Pegunungan Tunggilis. Ketika lidi dicabut kembali, batu itu timbul dan menonjol seperti alat kelamin laki-laki 
serta memancarkan air. Oleh karena itu, daerah tersebut kemudian dinamakan Paliken, yang berasal dari kata palakian (Sunda), yakni alat kelamin laki-laki. Setelah itu, Patih Sawung Galing menaburkan bibit tanaman tembakau, yang kemudian terkenal dengan tembakau Paliken (Adeng, 2011: 34).

Dewi Rengganis melihat sendiri kebenaran kekuatan dan kadigjayaan Sawung Galing. Akhirnya dia mempercayai sang patih, bahkan bersedia menerima lamaran untuk menikah dengannya. Walaupun Dewi Rengganis telah menikah dengan Sawung Galing, kelompok kesenian itu tetap berjalan. Setiap malam mereka mengadakan hiburan bersama para pemuda yang ada di pegunungan itu. Dalam berkesenian, Mama Lengser beserta Dewi Rengganis menyusun jalannya pertunjukan beserta lagu-lagunya berdasarkan kisah perjalanan Dewi Rengganis sejak berangkat, menghilang dari Kerajaan Pananjung Pangandaran.

Selain menyamar sebagai rombongan kesenian, mereka juga menjadi petani atau bercocok tanam bersama-sama dengan masyarakat di pegunungan itu. Pada waktu itu, bercocok tanamnya berpindahpindah, jadi tidak menetap. Dikisahkan sampailah mereka di suatu tempat yang kemudian disebut Bagolo. Di tempat itu rombongan Mama Lengser memaksakan ngahuma. Sementara itu, malam harinya tetap menggelar hiburan yang disebut mamarung (hiburan). Pertunjukan itu merupakan kesiapsiagaan mereka untuk melawan musuh-musuh yang mungkin akan masuk dan memboyong ronggengnya.

Dikisahkan rombongan Mama Lengser sedang menggelar mamarung, tiba-tiba serombongan bajo datang. Mereka memang sengaja terus menelusuri keberadaan sang dewi, dan mereka mengetahui yang dicari ada dalam rombongan tersebut. Namun, kali ini mereka mendapat perlawanan yang ketat. Oleh karena kekuatan rombongan Mama Lengser sudah disusun sedemikian rupa, dengan tenaga andalannya yaitu Sawung Galing, rombongan bajo pun dapat dikalahkan. Banyak di antara mereka mati dibunuh oleh Sawung Galing. Oleh karena kejadian itu, Mama Lengser menamakan tempat itu Bagolo, yang berasal dari kata begalan pati atau bertaruh nyawa dengan para bajo. Sampai sekarang tempat itu dikenal sebagai tempat untuk mencuci diri supaya kuat oleh pukulan benda keras dan tikaman benda tajam.

Akhirnya, Dewi Siti Samboja yang menyamar jadi ronggeng dengan nama Dewi Rengganis kembali bersama Sawung Galing ke kerajaan bekas Raden Anggalarang, yaitu ke Pananjung Pangandaran. Sejak itulah kerajaan tersebut dinamakan Pananjung Ngadeg Tumenggung, dengan rajanya Sawung Galing (Depdikbud Ciamis, 1998: 9).

\section{Beberapa versi Tari Ronggeng Gunung}

Terdapat beberapa versi tentang asal-usul kesenian ronggeng gunung, dua di antaranya adalah:

Versi pertama menurut masyarakat Ciamis Selatan (Panyuratan, Ciparakan, Barujul, Pangandaran, dan Cijulang) mengatakan bahwa, ronggeng gunung diciptakan oleh Raden Sawung Galing. Konon, ketika Kerajaan Galuh dalam keadaan kacau-balau karena ada serangan dari pihak musuh, kemudian Sang Raja terpaksa mengungsi ke tempat yang aman. Dalam keadaan situasi demikian, muncullah seorang penyelamat yang bernama Raden Sawung Galing. Raden Sawung Galing berhasil memukul mundur musuh Kerajaan Galuh. Atas jasa-jasanya maka Raden Sawung Galing dinikahkan kepada putri Sang Raja (Putri Galuh).

Kemudian, ketika Raden Sawung Galing memegang tampuk pemerintahan, beliau menciptakan sebuah tarian yang bernama ronggeng gunung sebagai sarana hiburan resmi di istana. Penarinya diseleksi ketat oleh raja dan harus betul-betul mempunyai kemampuan menari, 
menyanyi, dan berparas cantik, sehingga ketika itu penari ronggeng mempunyai status terpandang di lingkungan masyarakat.

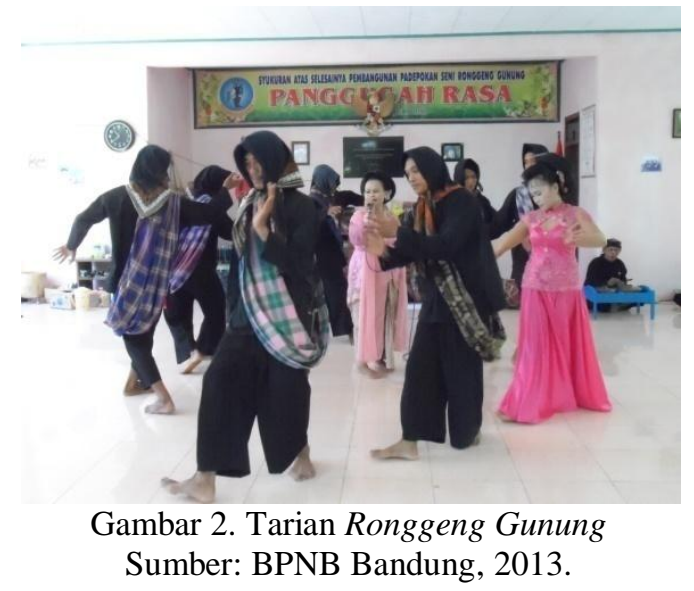

Versi kedua menceritakan perkawinan antara Dewi Siti Samboja dengan Raden Anggalarang, putra Prabu Haur Kuning dari Kerajaan Galuh. Perkawinan ini tidak direstui atau tidak disetujui oleh ayahanda, Raden Anggalarang. Raden Anggalarang mohon pamit dan izin kepada ayahnya Prabu Haur Kuning untuk mendirikan sebuah kerajaan di Pananjung, yaitu daerah yang kini merupakan Cagar Alam Pananjung di objek wisata Pangandaran. Prabu Haur Kuning merestuinya namun dalam hatinya merasa khawatir mendirikan kerajaan di Pananjung karena tempat itu sering didatangi para perompak. Kehawatiran Prabu Haur Kuning terbukti ketika Anggalarang mendirikan Kerajaan Pananjung tidak lama kemudian diserang oleh para perompak (bajak laut) yang dipimpin oleh Kalasamudra, sehingga terjadi pertempuran. Namun, karena pertempuran tidak seimbang, akhirnya Raden Anggalarang gugur. Akan tetapi, istrinya, Dewi Siti Samboja, berhasil menyelamatkan diri dan mengembara. Dalam pengembaraannya yang penuh dengan penderitaan, sang Dewi akhirnya menerima wangsit agar namanya diganti menjadi Dewi Rengganis dan menyamar sebagai ronggeng. Di tengah kepedihan hatinya yang sangat mendalam karena ditinggal suami yang dicintainya, Dewi Rengganis berkelana dari satu tempat ke tempat lainnya. Tanpa terasa, gununggunung telah didaki dan lembah-lembah dituruni. Namun, di matanya masih terbayang bagaimana orang yang dijadikan tumpuan hidupnya telah dibunuh para perompak dan kemudian mayatnya diarak lalu dibuang ke Samudera Hindia. Kepedihan itu diungkapkan dalam lagu yang berjudul "Manangis". Berikut ini adalah syairnya.

\section{Ka mana boboko suling}

Teu kadeuleu-deuleu deui

Ka mana kabogoh kuring

Teu kadeulu datang deui

Singkat cerita, pergelaran ronggeng akhirnya sampai di tempat Kalasamudra dan Dewi Samboja dapat membalas kematian suaminya dengan membunuh Kalasamudra ketika sedang menari bersama.

Cerita tersebut di atas mulai dari versi satu dan dua pada intinya sama, Dewi Samboga ingin membalas dendam atas terbunuhnya suami yang dicintainya oleh para perompak atau bajak laut yang dipimpin oleh Kalasamudra. Hanya alur ceriteranya yang berbeda (Andayani, 2006: $31)$.

\section{Raspi Sang Maestro Ronggeng Gunung}

\section{a. Latar Belakang Keluarga}

Raspi adalah seorang seniman ronggeng gunung yang cukup terkenal. Menurut Raspi ia lahir sekitar tahun 1956 di Dusun Karang Gowok, Kabupaten Ciamis, dari pasangan Sidot dan Kastem. Raspi hidup dalam keluarga yang sangat sederhana. Ketika orang tuanya bercerai, ia lebih memilih tinggal bersama ibunya di Dusun Karang Gowok.

Raspi mulai menggeluti dunia ronggeng sejak lulus SD sekitar tahun 1972, itu pun secara tidak sengaja. Saat itu di usianya yang baru 13 tahun, ia lari dari rumahnya sebagai wujud pemberontakannya karena dipaksa oleh orang 
tuanya untuk menikah dengan lelaki bukan pilihannya, sementara dia merasa belum siap untuk menikah muda.

Pada saat pelarian itu ia bertemu dengan pelatih ronggeng, yaitu mbah Maja Kabun dan Indung Darwis di Kampung Jublek, Desa Panyutran, Kecamatan Padaherang. Mbah Maja Kabunlah yang menjadi guru pertamanya mempelajari tari ronggeng gunung, namun secara spiritual disempurnakan oleh Indung Darwis. Menurut Bi Raspi, Indung Darwis adalah gegedug atau ahlinya ronggeng $\mathrm{di}$ Padaherang. Teman seangkatan Bi Raspi saat itu adalah Bi Pejoh dan Bi Atih dari Pagergunung Pangandaran (http://www. kabar-priangan.com/ews/detail/11217/ diakses 9 Januari 2014).

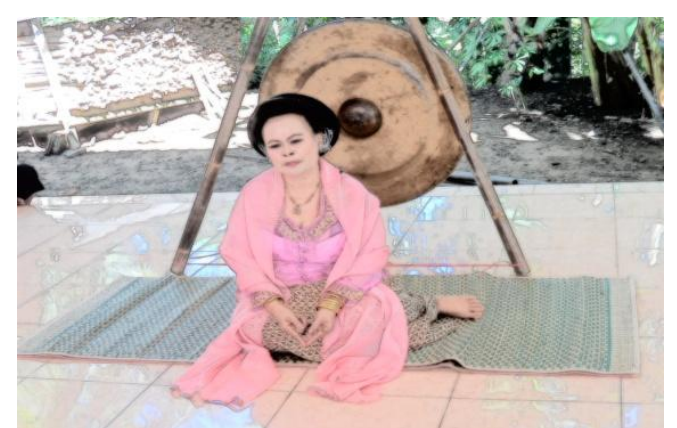

Gambar 3. Bi Raspi Sang Maestro Sumber: BPNB Bandung

Pada tahun tersebut keberadaan ronggeng gunung sangat dipuja dan dihormati di kalangan masyarakat (Yuniawati, 2009: 3). Ronggeng gunung biasanya diadakan pada acara ritual, seperti ruwatan lembur, sedekah bumi, parasan bayi, syukuran sehabis panen, mau menanam padi, dan lain-lain. Di saat Raspi muda, ronggeng gunung adalah satusatunya hiburan dan sangat dihargai keberadaannya.

Saat usia dewasa, Raspi mengalami dua kali pernikahan. Yang pertama ia menikah dengan Dahlan yang kemudian membawanya pindah tempat tinggal ke daerah Ciulu, Ciamis. Dari pernikahan tersebut lahir putrinya yang bernama Nani Nurhayati, ia merupakan putri satu-satunya Raspi. Akan tetapi sayang, pada akhirnya pernikahan itu diakhiri dengan perceraian. Selanjutnya Raspi menikah lagi dengan salah seorang nayaga Sanggar Panggugah Rasa, sanggar seni yang dipimpinnya yaitu Wasco.

Untuk pementasan di daerahnya biasanya Raspi hanya tampil seorang diri, karena nayaga dan penari pengiringnya berasal dari penonton yang spontan menabuh alat musik sederhana berupa kenong dan menari mengiringi Raspi. Namun karena akhir-akhir ini Raspi sering diundang untuk tampil di luar daerahnya maka diperlukan adanya personil tetap yang dapat mengiringinya mementaskan ronggeng gunung di mana saja dan kapan saja dipentaskan. Kemudian dibentuklah sebuah sanggar seni yang bernama "Panggugah Rasa" miliknya. Kesenian ronggeng gunung ini tetap masih bisa tampil walaupun dalam kondisi yang semakin sulit seperti saat ini.

Raspi kini masih aktif me-ronggeng di daerahnya untuk acara hajatan dan ritual. Selain berpentas di daerah dan sekitarnya, Raspi juga pernah dipanggil untuk berpentas hingga ke Taman Mini Indonesia Indah (TMII).

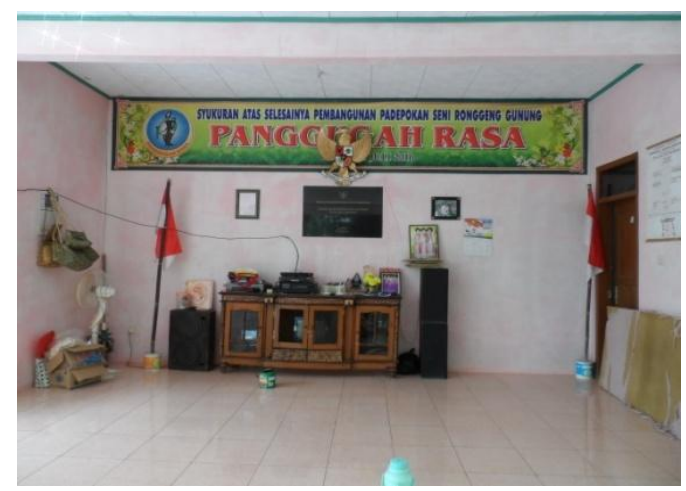

Gambar 4. Sanggar Ronggeng Gunung Panggugah Rasa

Sumber: BPNB Bandung, 2013. 
Secara struktural kepengurusan sanggar seni Panggugah Rasa memiliki struktur organisasi sebagai berikut:

$\begin{array}{lll}\text { Nama } & : & \begin{array}{l}\text { Lingkung Seri } \\ \text { Tradisional } \\ \end{array} \\ & & \text { Ronggeng } \\ & \text { Gunung } \\ & & \text { "Panggugah } \\ & & \text { Rasa" } \\ \text { Pelindung } & : & \text { Kepala Desa } \\ \text { Penasehat } & : & \text { Sarji Kusmayadi } \\ & & \text { Gusnadi S. Pd. } \\ & & \text { MM, } \\ \text { Ketua I } & : & \text { Raspi } \\ \text { Ketua II } & : & \text { Kaspan } \\ & : & \text { Oma Kusmera } \\ & & \text { Am. Pd. } \\ \text { Sekertaris II } & : & \text { Tarjo } \\ \text { Bendahara } & : & \text { Nani } \\ \text { Pelatih } & : & \text { Raspi } \\ & & \text { Dedi Supriadi } \\ \text { Nayaga } & : & \text { Tarja } \\ & & \text { Oceh } \\ & & \text { Tarjo } \\ \text { Penari } & : & \text { Kasja } \\ & & \text { Kaspan } \\ & & \text { Ade S. } \\ & & \text { Ade Sarsih } \\ & & \text { Oji } \\ & & \text { Karsu } \\ & & \text { Naryo Mahro } \\ & & \text { Nedo } \\ & & \text { Taslim } \\ & & \end{array}$

(Panggugah Rasa, 2012: 10)

\section{b. Raspi Penari Ronggeng Gunung}

Seperti telah diuraikan di atas bahwa Raspi belajar tari ronggeng gunung kepada Embah Maja Kabun dan Indung Darwis. Saat itu Raspi datang ke tempat latihan ronggeng hanya untuk melihat temannya yang sedang berlatih. Akan tetapi kemudian Raspi mulai mengikuti latihan ngibing. Melihat potensi seni yang dimiliki oleh Raspi, Embah Maja Kabun menyarankan Raspi untuk ikut berlatih tari ronggeng. Semenjak itu ia mulai mengikuti latihan tari ronggeng dan nyinden. Ia berlatih nyinden kepada sinden ronggeng gunung zaman itu, yaitu Indung Darwis (Wawancara dengan Raspi, 19 Mei 2013).

Setelah tamat belajar dari Maja Kabun, Raspi mulai "dilamar" atau istilahnya ngala ronggeng untuk tampil pertama kalinya sebagai ronggeng gunung. Sebelum tampil untuk pertama kalinya ia dimandikan di mata air keramat yang berada di Kabuyutan Kawasen. Proses ini merupakan titik awal bagi seorang ronggeng gunung untuk menunjukkan kemampuannya. Tidak hanya kemampuan lahir seperti hafal semua lagu ronggeng gunung yang memiliki urutan baku, serta olah vokal yang prima, tetapi juga menguji kemampuan batin seorang ronggeng gunung yang dianggap sakral. Hal ini dilakukan karena fungsi seorang ronggeng gunung tidak saja sebagai penghibur tetapi juga merangkap sebagai sosok yang mampu meruwat, yang dianggap memiliki kemampuan supranatural. Sejak itu Raspi menjadi ronggeng gunung yang tetap eksis sampai sekarang (http://www.kabarpriangan.com/ews/detail/11217/diakses 9 Januari 2014).

Sekitar 46 tahun sudah Raspi menjalani kehidupan sebagai penari ronggeng gunung. Ia merupakan salah satu sosok seniman ronggeng gunung yang lama bergelut dalam bidangnya. Ia pernah merasakan dibayar dari 200 rupiah sampai 3 juta/pertunjukan. Tahun 1970-1980 merupakan masa keemasan tarian ronggeng gunung. Saat itu menurut Raspi,

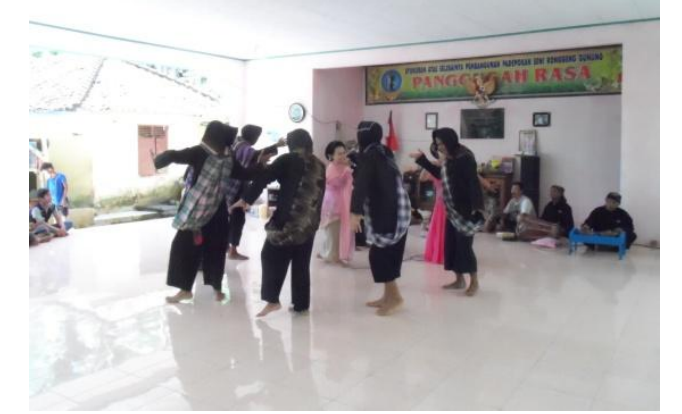

Gambar 5. Tarian Ronggeng Gunung Sumber: BPNB Bandung, 2013. 
ia selalu merasa kewalahan memenuhi panggilan pentas. Ia hanya punya waktu istirahat 3 sampai 7 hari dalam sebulan. Waktu-waktu padat itu terutama di saat usai panen atau musim menggelar hajat perkawinan atau khitanan.

Menurut Raspi seni tari yang awal berkembangnya dari daerah Pangandaran ini tidak mudah untuk dipelajarinya. Mempelajari tarian ronggeng gunung harus memiliki fisik yang kuat, karena ronggeng gunung harus memiliki kemampuan olah vokal dalam nada tinggi sekaligus menari dalam waktu yang lama. Ronggeng gunung biasanya dipentaskan 2 sampai $12 \mathrm{jam} /$ pertunjukan. Dalam satu pertunjukan biasanya dibawakan 6 sampai 8 lagu, antara lain lagu Kudup Turi, Sisigaran Golewang, Raja Pulang, Kawungan, Parut, dan Srondol. Mayoritas lagunya bertema kerinduan kepada kekasih dan sindiran pada perompak yang telah membunuh Anggalarang.

Kesulitan lain mempelajari seni tradisi ini menurut Raspi karena tembang yang biasa dibawakan, syair lagunya tidak dibukukan. Lagu-lagu yang didapatkannya dipelajarinya secara otodidak, yaitu dihafalkan.

Oleh karena berbagai kendala tersebut pada era tahun 90-an ronggeng gunung mulai tenggelam di tengah kehidupan modern. Orang lebih memilih nanggap organ tunggal dibanding kesenian tradisi.

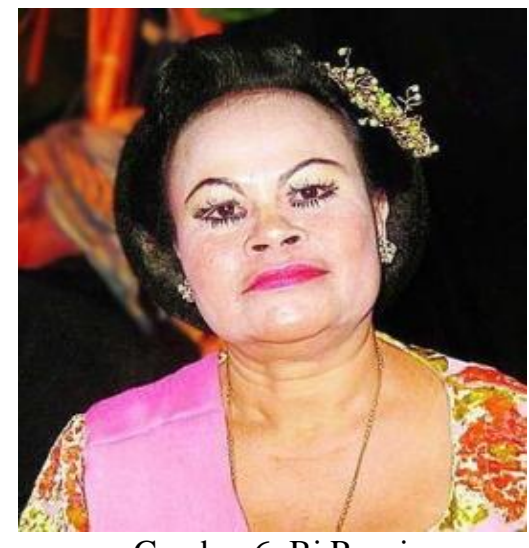

Gambar 6. Bi Raspi

Sumber: Kompas, 2011.

\section{c. Upaya Regenerasi Ronggeng Gunung}

Kesenian ronggeng gunung merupakan khasanah budaya lokal yang harus dilestarikan karena merupakan aset besar budaya Kabupaten Ciamis. Sudah saatnya pemerintah terlibat untuk mensosialisasikan kesenian ronggeng gunung kepada generasi muda, agar tidak melupakan jati dirinya. Upaya yang dilakukan oleh pemerintah daerah setempat nampaknya tidak dapat berbuat banyak, kecuali menampilkan kesenian tersebut di even tertentu seperti hari-hari besar nasional dan itu pun semakin jarang dilakukan.

Proses regenerasi yang dilakukan oleh Raspi pada saat ini kelihatannya juga tidak berjalan seperti yang diharapkan. Upaya tersebut mengalami hambatan antara lain kurangnya minat generasi muda untuk mempelajari seni ronggeng gunung. Menurut Raspi bahwa sebenarnya ia ingin mempunyai murid yang banyak sebagai penerus dirinya, tetapi jangankan orang lain, anaknya sendiri pun belajarnya kurang serius.

Nani Nurhayati putrinya, belum mampu maksimal seperti dirinya yang berperan sebagai penari dan juru tembang yang harus mampu membawakan tembang dengan vokal melengking. Nani, putrinya baru berani tampil sebagai ronggeng gunung apabila didampingi oleh ibunya (Wawancara dengan Nani, 19 Mei 2013).

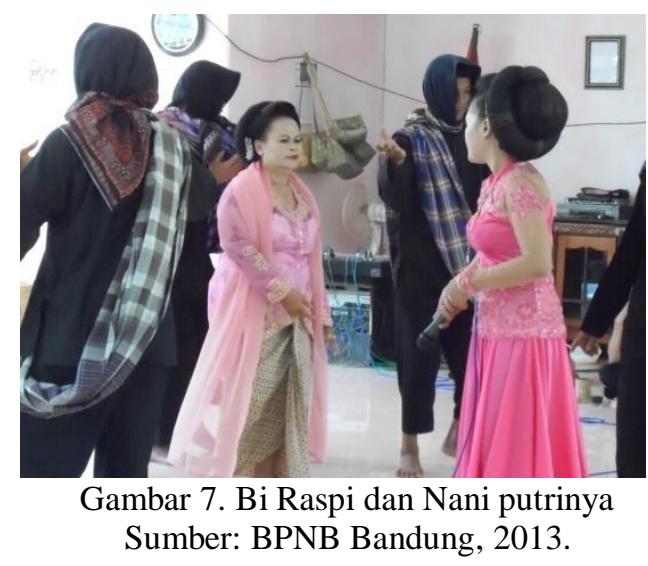

Sebagai salah satu upaya untuk melestarikan keberadaan kesenian ronggeng gunung, Raspi dengan Sanggar 
Seni Panggugah Rasa mencoba untuk membuat variasi terhadap kesenian ronggeng gunung yang identik dengan religius, dengan mencoba keluar dari pakem utamanya. Apabila ronggeng gunung hanya dapat ditampilkan pada kegiatan-kegiatan tertentu yang bersifat ritual atau resmi maka dibentuklah ronggeng kaler sebagai variasi lain dari ronggeng gunung untuk menjawab keinginan masyarakat terhadap kesenian tradisional yang memiliki sifat hiburan (Nopianti, 2015: 89).

\section{d. Penghargaan}

Walaupun di era globalisasi ini keberadaan kesenian ronggeng gunung kurang berkembang, namun Raspi selaku tokoh kesenian ronggeng gunung mampu mempertahankannya agar kesenian tersebut tetap tumbuh, lestari, dan berkembang dalam kehidupan masyarakat .

Berkat ketekunan dan tekadnya untuk tetap melestarikan seni tradisi karuhun ronggeng gunung telah membawa Raspi melanglang buana dan mendapat berbagai penghargaan. Ia pernah diutus ke Amerika sebagai duta pariwisata, kemudian 25 Oktober 2013 ia diajak oleh seniman rupa dari ITB, Tisna Sanjaya untuk tampil di Singapura di acara Bienalle Singapore 2013 dengan membawakan 13 tembang yang digelar semalam suntuk. Raspi pun diajak oleh perusahaan Djarum. Pada tahun 2013 Djarum menyediakan 8 panggung, dan memberikan 11 panggung di tahun 2014 untuk ronggeng gunung. Ia juga tercatat sebagai dosen luar biasa di salah satu universitas di Bandung.

Beberapa penghargaan yang didapat Raspi adalah:

- Tahun 1997 dari Taman Mini Indonesia Indah.

- Tahun 2007 mendapat medali kesenian dari Gubernur Jawa Barat, Dani Setiawan.

- Tahun 2009 ia mendapat bantuan dana sebesar 200 juta dari Pemerintah Provinsi Jawa Barat pada masa
Gubernur Dani Setiawan untuk pembuatan padepokan seni.

Saat ini dalam setiap pertunjukan Bi Raspi hanya bisa duduk di samping para nayaga dan melakukan ngawih. Sementara ngibing dilakukan oleh Nani, puterinya dan Desi, cucunya. Nani sebagai pewaris ronggeng gunung belum bisa total seperti ibunya, belum bisa tampil tanpa kehadiran ibunya (Sutrisna, 2015: 10).

\section{PENUTUP}

Dalam kerangka kebudayaan nasional, seni tradisi merupakan aset bangsa yang tidak ternilai, salah satunya dapat dimanfaatkan untuk kepentingan pariwisata Indonesia. Semua jenis kesenian tradisional yang ada memiliki hak untuk hidup, berkembang, dan diapresiasi oleh bangsa Indonesia serta mendapat ruang dalam konteks kepariwisataan Indonesia. Namun tentu saja tidak mudah untuk mewujudkan hal itu, terbukti hanya sedikit seni tradisi yang dapat menikmati kondisi seperti itu. Selebihnya, harus hidup dalam serba keterbatasan, baik pemain, penonton, peralatan, dan kesempatan untuk mengekspresikan diri. Perlakuan yang diskrimiatif, mengistimewakan kesenian tradisional yang satu dan menganaktirikan kesenian tradisional lainnya, masih kerap dilakukan oleh masyarakat secara individu maupun kelembagaan, baik swasta maupun pemerintah.

Kesenian ronggeng gunung Bi Raspi merupakan salah satu kesenian tradisional asli Jawa Barat, tepatnya di Kampung Cikukang, Desa Ciulu, Kecamatan Banjarsari, Kabupaten Ciamis Selatan. Kesenian ini masih bertahan di tengahtengah pergulatan antara kesenian modern dan kesenian tradisional pada zaman sekarang. Kesenian ini mampu bertahan tidak lepas dari upaya Bi Raspi untuk dapat melestarikan ronggeng gunung tersebut. Ia tokoh seniman ronggeng gunung yang masih setia dan bertahan dengan kesenian buhun ini.

Sampai saat ini ronggeng gunung Bi Raspi tidak banyak mengalami perubahan 
mencolok. Perubahan hanya terlihat dari cara penyajian ronggengnya. Dahulu ronggengnya hanya satu orang tetapi sekarang bisa menjadi 2 atau lebih, tetapi juru kawihnya tetap hanya Bi Raspi yang mampu melakukan dengan suara yang melengking menyayat hati. Rias dan busana juga mengalami perubahan dengan menggunakan kebaya modern, sematamata hanya untuk menarik minat masyarakat agar mencintai budayanya.

Mengikuti perjalanan ronggeng gunung Bi Raspi dapat dibagi dalam 4 fase, yaitu:

1. Masa 1972-1980, masa awal karir Bi Raspi.

2. Masa 1980-1989, masa keemasan.

3. Masa 1990-1999, masa vakum.

4. Masa 2000-2009. masa bangkit.

Tentang polemik ronggeng gunung yang diperebutkan oleh Kabupaten Ciamis dan Kabupaten Pangandaran, Bi Raspi mengaku prihatin. Menurutnya pihak pemerintah tidak perlu terjebak oleh asal muasal ronggeng gunung. Seharusnya semua pihak sepakat untuk melestarikan seni budaya warisan Kerajaan Galuh ini.

Kesenian ronggeng gunung masih tetap konsisten. Pihak pemerintahan pun memberi ruang agar kesenian tersebut tetap hidup dan berkembang, misalnya dengan melibatkannya pada acara sosialisasi suatu program pemerintah, atau tampil pada acara syukuran atau peringatan tertentu di suatu instansi pemerintah. Langkah tersebut tampaknya belum cukup menyentuh akar permasalahannya agar kesenian khas Kabupaten Ciamis ini lepas dari ancaman kepunahan. Masih harus dicari solusi dari masalah tersebut agar kesenian tradisional warisan leluhur di Kabupaten Ciamis itu dapat tetap dinikmati dan ditonton sampai kapan pun. Yang lebih penting lagi, perlu adanya pendokumentasian tentang gending dari tari ronggeng gunung yaitu dengan cara dinotasikan secara lengkap kemudian dibukukan sebelum benar-benar punah.

\section{UCAPAN TERIMA KASIH}

Penulis mengucapkan terima kasih kepada Kepala Dinas Kebudayaan dan Pariwisata Kabupaten Ciamis yang telah memberi informasi awal mengenai kesenian tradisional ronggeng gunung.

Ucapan terima kasih juga penulis sampaikan untuk keluarga $\mathrm{Bi}$ Raspi khususnya yang telah menerima kehadiran penulis dengan baik, serta semua pihak yang telah memberikan bantuan pada saat penelitian tersebut.

\section{DAFTAR SUMBER}

\section{Jurnal dan Skripsi}

Campaka, Gilang. 2008.

Lagu Kudup Turi dalam Kesenian Ronggeng Gunung di Ciamis Selatan. Skripsi. Bandung: UPI.

Herawati, Yanti. 2005.

Ronggeng Gunung Ritual dan Spirit yang Menjadi Liminal" dalam Jurnal Panggung XXVIII.

Nopianti, Risa. 2014.

"Dari Ronggeng Gunung ke Ronggeng Kaler: Perubahan Nilai dan Fungsi", dalam Patanjala Vol.6 No.1, Maret 2014, hlm. 81-92. Bandung: BPNB Bandung.

Yuniawati, Yayu. 2009. Perjalanan Ronggeng Gunung di Ciamis. Skripsi Bandung: FPBS UPI.

\section{Buku}

Adeng et al. 2011.

Sejarah Ronggeng Gunung. Bandung: BPNB Bandung.

Andayani, Ria et al. 2006.

Ronggeng Gunung: Menggali Seni Tradisi bagi Pengembangan Pariwisata dan Seni Modern di Kabupaten Ciamis. Bandung: BKSNT Bandung.

Badan Pusat Statistik Ciamis. 2016. Ciamis dalam Angka 2016. Ciamis: BPS.

Depdikbud Kabupaten Ciamis. 1998. Pangandaran dan Ronggeng Gunung. Ciamis: Seksi Kebudayaan Depdikbud Ciamis. 
Herdiani, Een. 2003.

Bajidoran di Karawang Kontinuitas dan Perubahan-perubahan. Jakarta: Hasta Wahana.

Holt, Claire. 2000.

Melacak Jejak Perkembangan Seni di Indonesia. Terjemahan R.M.

Soedarsono. Bandung: Arti LineMSPI.

Rosidi, Ajip et al. 2000.

Ensiklopedi Sunda, Alam, Manusia, dan Budaya. Jakarta: Pustaka Jaya.

Sutrisna, Angra. 2015.

Bi Raspi: Pelestarian Kesenian Ronggeng Gunung Ciamis. Surakarta: Fakultas Seni Pertunjukan Institut Seni Indonesia.

Tim Penyusun Kamus. 2005.

Kamus Besar Bahasa Indonesia, Jakarta: Balai Pustaka.

Panggugah Rasa. 2012.

Sejarah Singkat Ronggeng Gunung.

Ciamis: Lingkung Seni Panggugah

Rasa.

\section{Sumber Lisan/Informan}

Bi Raspi (56 thn). 2013.

Maestro seni ronggeng gunung.

Wawancara, Kabupaten Ciamis, 19 Mei 2013.

Nurhayati, Neni (25 thn). 2013.

Seniman ronggeng gunung.

Wawancara, Kabupaten Ciamis, 19 Mei 2013.

\section{Internet}

"Raspi Ronggeng Gunung Terakhir" dalam https://www.facebook.com/notes/panduradea/raspi-ronggeng-gunungterakhir/10152123872181339/ diakses, 18 Juli 2016/pukul 15:11.

"Titik Balik Perjalanan Nyi Ronggeng” diakses dari http://www.kabarpriangan.com/news/detail/11217 diakses 9 Januari 2014.

"Raspi: Maestro Ronggeng Gunung Terakhir", dalam http://indonesiaproud.wordpress. com/2011/01/11/raspi-maestroronggeng-gunung-terakhir/ diakses 9 Januari 2014.
"Sinden Ronggeng Asal Ciamis akan Go Internasional", dalam http://www.ciamismanis.com/2013/10/si nden-ronggeng-asal-ciamis-akango.html\#.Us4ekftGbOE/ diakses 9 Januari 2013.

“Ronggeng Gunung Bi Raspi dan pergantian", dalam http://catatancatatanmalam .blogspot.co.id/2012/01/ronggenggunung-bi-raspi-dan-pergantian.htm / diakses 20 Juli 2016 pukul 19:44 